\title{
Gendering \\ Low-Carbon Life \\ among Retirees in \\ Urban China
}

By Nikolaj Vendelbo Blichfeldt

\begin{abstract}
Gendering Low-Carbon Life among Retirees in Urban China

The aim of this article is to examine how questions related to age and gender become articulated in a climate change mitigation campaign based in an urban residential community in Hangzhou in eastern China. Based on ethnographic fieldwork in the community, the article presents a case study of this campaign. A group of community officials and retired residents are promoting 'low-carbon life', their aim being to alter a range of everyday consumption practices. During the campaign, a handful of retired women emerged as campaign role models and leaders of campaign activities, as well as producing 'low-carbon handicrafts' made from reused materials. The campaigners are approaching low-carbon life as a set of enjoyable hobby-like activities where women in particular reactivate skills acquired during the Mao era, thus coming to be seen as role models by local officials and journalists. The study contributes to the emerging field of climate ethnography by illustrating how a group of Chinese citizens make sense of climate politics by recasting climate-related issues, connecting these to their everyday life concerns and engaging in practical campaign work anchored in local material culture.
\end{abstract}

\section{KEYWORDS}

Climate change, campaign, low-carbon life, role models, community, consumption

Nikolaj Blichfeldt holds a PhD in China Studies from the Institute of Cross-Cultural and Regional Studies, University of Copenhagen. His research interests include climate change, environmentalism, everyday life and civil society in China. 


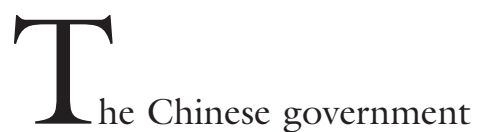
has initiated climate change mitigation programs in a number of provinces and cities. In recent years Hangzhou, the capital of Zhejiang Province in eastern China, has become known as a city at the forefront of the development of climate change mitigation strategies. One dimension of the climate strategy in Hangzhou is to address the everyday consumption practices of citizens through various campaigns (Delman 2014). In the residential community of Dongping Lane in central Hangzhou, a local campaign began in 2010 when Little Zheng, a young community official, responded to the calls of the municipal government for climate change mitigation at the grassroots level by launching a competition to become 'Low-Carbon Model Households' (低碳家庭示范户). Among the participating residents, a small group of older women quickly emerged as core campaigners, contributing with ideas, organizational work and the staging of exhibitions of 'low-carbon handicrafts' (低碳手工艺品) made from reused materials. Focusing on saving energy and resources, the competition was carried out according to a standard developed in collaboration between officials and residents through a series of lectures and meetings. It was followed by a garbage sorting competition, excursions to a local landfill site, and a series of workshops focusing on the production of handicrafts from recycled materials. The campaign has been covered by both the local and national media.

Focusing on the ways in which campaign participants make sense of their activities as responses to climate change, I have examined what happens when universalizing claims about global climate change encounter local ways of knowing the world in a particular locality, in this case an urban residential community in China. As a result of this focus, the gendering of campaign exemplarity and the renegotiation of citizen roles for retired residents have emerged as themes. The location determined the age group under study, first because most residents are retired, and secondly because community-based campaigns in China mostly reach older people. The focus on a specific group of people in a specific location means that the material cannot be used to make general claims about the state of popular climate change mitigation in China, nor can it predict how the growing middle-class in China will respond to calls for climate change mitigation. Instead, the material generated in this ethnography can provide a view of local processes of developing and making sense of climate change mitigation practices, which may indicate some of the concerns and sensibilities that come to the fore when the global issue of climate change is addressed through local action and sense-making in the residential communities of urban China.

\section{ETNOGRAPHIC FIELDWORK IN DONGPING LANE}

Dongping Lane is a small urban community with approximately 5500 residents registered in around 2000 households. Twothirds of the residents are retired. Around 200 households have earned the designation 'Low-Carbon Model Household', and around 600 have participated in the garbage sorting scheme. ${ }^{1}$ A handful of people have gained a reputation for being especially knowledgeable about energy saving, recycling and garbage sorting. They also stand out as the most visibly active among the participants in the campaign. Promoted by media and local officials as role models, they have become the public faces of the campaign. A significant majority of campaign participants and nearly all of the role models are middle-aged or older women.

I carried out eight months of ethno- 
graphic fieldwork in the community in 2011 and 2012 interviewing residents, local officials, journalists and experts involved in the campaign, observing the campaign work of the local community office, participating in local events such as neighborhood festivals, and reading documents and articles related to the campaign. ${ }^{2}$ The motivation for choosing Dongping Lane as the fieldwork site for the study came from a series of articles in the Chinese media about the low-carbon life campaign that was being carried out there (see, for example, $\mathrm{Xu}$ 2010). These articles indicated that the community could be a promising site for investigating some of the ways in which citizens in urban China are responding to global climate change.

The 'low-carbon life' campaign in Dongping Lane has been conceived as a project that depends on the voluntary participation of residents. It is mainly older residents who have taken up and promoted the lifestyle changes proposed in the campaign. The competition to become model households was primarily a form of propaganda serving to promote the campaign. There is little indication that it was taken entirely seriously by the residents as a vision for the future of urban China. Instead, the Low-Carbon Household Standard (Figure 1) developed for the competition has come to serve as a tentative catalogue of everyday life practices that may need rethinking in the new era of anthropogenic climate change.

The Standard connects climate change with an array of everyday objects and substances: garbage, shopping bags, food, plants, light bulbs, air conditioners, water, gas, bicycles and cars. Participants can earn points by sorting their garbage, bringing their own bags when shopping, eating a vegetarian meal once a week, keeping more than ten plants in the home, using energysaving light bulbs, setting the air conditioner to no lower than 26 degrees Celsius in summer and no higher than 18 in win- ter, using less water and gas, and taking the bus or cycling instead of driving.

Although the campaign participants are sincerely trying to save energy and resources, there is an air of make-believe about the Low-Carbon Model Household competition, as it sets up a space of exception, generating an 'as if world' in which climate change appears as a simple problem that campaigning can solve. To some extent mimicking earlier campaigns, the competition can be seen as partly a rituallike undertaking in which the residents of Dongping Lane have an opportunity to see themselves as people who matter to the overall development of Chinese society and who can contribute meaningfully to the gargantuan task of preventing the world from heading to climate disaster. The work performed by this kind of ritual-like activity is intended to alter local social relationships on the basis of experiencing the harmony of a make-believe world free of contradictions and complex problems. The point of the Low-Carbon Household Standard, then, is not for people to believe in it as an actual solution. It provokes thoughts exactly because of the disjunction between the overwhelming challenges posed by global climate change and the simple solutions it offers by highlighting the everyday lives of ordinary people and bracketing such issues as the climate politics of industry and government.

Rather than engage in political lobbying, public protests or attempts to put pressure on businesses or fellow citizens, campaigners have generally approached low-carbon life as a series of hobby-like activities, not unlike popular 'life-nurturing' yangsheng (养生) activities like big-brush calligraphy, ballroom dancing, walking backwards and taking caged birds to the park, widely embraced by older people in urban China (Farquhar and Zhang 2012). Taken together with the demographic composition of the community, as well as the tendency for older people to respond more 


\section{Figure 1}

\section{Dongping Lane Community Low-Carbon Household Standard (东平巷社区低碳家庭标准)}

Life

(33 points)

Electrical

appliances

(33 points)
The household must participate in the garbage sorting scheme (4-10)

Bring your own bag when shopping, don't use plastic bags ( 5 points)

Eat less meat, eat more vegetables, eat vegetarian food once a week

(5 points)

Keep more than ten potted plants in the home ( 5 points)

Don't use paper cups, doggy bags or disposable chopsticks ( 5 points)

Exercise more outside, go less to the gym ( 3 points)

All light bulbs in the home must be energy-saving bulbs (10 points)

$70 \%$ of electricity consumption must come from electricity-saving appliances (7 points)

Unplug electrical appliances when they are not in use ( 5 points)

Open the windows in summer to cut in half the time using air conditioning (5 points)

Set air conditioners to 26 or above in summer and 18 or below in winter (5 points)

Use piped gas instead of buying gas cylinders - if installed in the building

Water and gas

(28 points)

(3 points)

Use $10 \%$ less gas (10 points)

Don't drink bottled water ( 5 points)

Reuse water $-15 \%$ of water must be reused (10 points)

Transportation Use public transport for $60 \%$ of all trips (10 points)

(16 points)

Reduce the number of days you drive to work, take public transport instead (6 points)

Keep a low-carbon journal and write in it once a week ( 5 points)

Extra points

(25 points)
Come up with five new carbon reduction tips every three months ( 5 points)

Set the air conditioner above 28 in summer and below 16 in winter (5 points)

Use renewable energy, e.g. solar water heaters ( 5 points)

Increase the number of plants in the home by $50 \%$, keep plants all year round ( 5 points)

Remarks: the maximum score is 110 points, the maximum amount of extra points is 25 , households scoring 95 points are awarded the status of first-level model households, households scoring 90 points are second-level model households, and households scoring 85 points are third-level model households. 
positively to community-based campaigning in China, the idea of low-carbon life as a series of hobby-like activities can go some way towards explaining the predominance of older residents in the campaign, but it does not explain the predominance of women. In order to explain how the campaign has become gendered, it is necessary to examine it in the contexts of material culture, changing state-society relations, changing notions of exemplarity, and connections with the media.

\section{AsSEMbling Low-CARbON LiFE IN Dongring Lane}

As a response to global climate change, the campaign in Dongping Lane has connected a range of everyday life practices and concerns about leading good lives in early $21^{\text {st }}$ century China. The material culture of reform-era urban China, which has gravitated towards consumerism following decades of rapid economic growth and the rise of a new urban middle class, has been implicitly challenged and rendered problematic to the low-carbon life campaigners by their growing awareness of connections between everyday consumption practices and climate change.

The low-carbon life campaign in Dongping Lane can be viewed as a site of technological, political and ethical renegotiation of what it means to be a proper citizen at the historical, political, and economic conjuncture of the late-reform era and the beginning of Chinese engagements with global climate change. As such it is an example of the kinds of sites which Ong and Collier refer to as global assemblages (Ong and Collier 2005). The set of practices outlined in the Low-Carbon Household Standard (Figure 1) has been produced as young officials have come together with retired residents of the generation that came of age during the Mao era to form a campaigning community. Through their campaign work, they have established con- nections between everyday life practices, the institutional organization of life in the residential community and global climate change. As the low-carbon life campaign has grown in scope and significance, it has become increasingly central to local understandings of citizenship because it is one of the most visible arenas where community officials and retired residents negotiate their relationships.

As climate change becomes an issue of concern, the residents of Dongping Lane find themselves placed in a new situation in which the lifestyle of relative comfort and affluence they have recently embraced has been called into question. This can be seen as representing an attempt to re-moralize areas of life that used to be public and highly moralized in the Mao era but had become increasingly private in recent decades. In Dongping Lane, climate change mitigation and notions of citizenship have become entangled for the campaign participants, as low-carbon life has come to stand as an expression of proper citizenship in early $21^{\text {st }}$ century urban China. What the practitioners of low-carbon life are enacting, then, is a citizen's role that reflects the assemblage of social life, politics and natural processes that informs the notion of climate change.

A crucial context for the constitution of the low-carbon life campaign is the process of urban reform in the 1990s, when many state-owned enterprises closed down, leading to a massive reorientation of urban life from being organized and imagined around work units (单位) to being organized and imagined as life in the residential community (Bray 2006). Organizational work in the residential communities of urban China has been dominated by middle-aged and older women in the past, and this tendency was reproduced when residential communities became administrative units (Heberer 2009: 500). The fact that the low-carbon life campaign is organized by the local community office as a series of voluntary 
activities for local residents means that those who respond to the call are mostly retired people who have the time to become involved and are interested in the idea of engaging in voluntary work, not only to address the issue of global climate change, but also to promote a civic culture and a sense of belonging to the residential community. Community offices in urban China have succeeded in connecting with the older part of the population, whereas younger people tend to orient themselves more toward real estate agencies when it comes to community affairs (Boland and Zhu 2012).

For the retired residents, making sense of climate change mitigation involves sorting out a repertoire of practices from their formative years in the era of high socialism - when Mao Zedong was the paramount leader and revolution was the keyword of politics - to determine what can be used in the present campaign. Some organizational forms and practices are tainted by their association with mass mobilization and class struggle, while other, less confrontational practices can be recycled. Specifically, the production and promotion of handicrafts made from reused materials have contributed to the gendering of the image of the exemplary campaigner, which has been produced in encounters between local officials, campaigning residents and visiting journalists.

\section{The Role of Women \\ IN LOW-CARBON LIFE}

In recent years there has been a growing awareness within both academia and policymaking circles of the ways in which various connections between global climate change and humans are gendered. ${ }^{3}$ The information material about the low-carbon life campaign in Dongping Lane contains no references to gender, nor any reflections on the specific role of men and women, and my informants in the community did not take the initiative to address gender issues when explaining their understanding of the aims and rationale of the campaign. There is, however, a majority of women among the campaigners, and this female predominance is especially pronounced among campaign role models. When confronted with these facts, informants offered analyses that shed light on the interconnectedness of climate change and social life by revealing the social categorizations, assumptions about social categories and promotion of identities that underlie their approach to climate change (Kaijser and Kronsell 2013).

Informants have different strands of explanation for the significant majority of female campaigners. Some stress connections between women and housework, especially for the older generations, and some associate women with a more careful and detail-oriented approach to everyday consumption practices. Following these explanations may show how the low-carbon life campaign is marked by a gender division of labour.

Explanations offered by informants point out that, as most domestic work is carried out by women, the resource consumption of the utilities and various electrical appliances in the home are most strongly influenced by women. Patterns of household resource management around the world are gendered and dynamic as more women make the consumption decisions within households (Dankelman 2002: 25). According to the campaigners, women of the older generations are often the main decision-makers regarding energy and resource consumption in households. One informant summarized this in the popular saying 'The man manages the outside, the woman manages the inside' (男主外女主内 ), meaning that the man goes out to work, while the woman looks after the house. She saw this as conducive to low-carbon life because she considered women to be more careful resource managers and expected 
men to follow the decisions of women in the supposedly small domestic matters that make up the majority of low-carbon life practices. Other informants made it clear that the situation in their household, did not follow the traditional patterns suggested by the saying, and the fact that many campaigners are retired means that the male participants spend more time at home and participate more in domestic work than they did in their youth. ${ }^{4}$

Apart from a quantitative argument about more women than men doing domestic work, some residents of Dongping Lane also expressed the view that women have a qualitatively different approach to domestic work compared with men. One young woman, who is both a resident and a community official, remarked that her husband sometimes cooks, but that he is much less conscious about sorting the kitchen waste in the process than she is. She ascribed this to his gender, speculating that men pay little attention to the materials they use at home, finding it somewhat unmanly to do so. Another woman linked the point from the Low-Carbon Household Standard (Figure 1) about bringing your own bag when shopping to gender, saying that most men would find it unmanly to bring a bag. She went on to relate shopping bags to age, pointing out that some of the older women in the community do not use bags at all when shopping but prefer woven baskets.

This view of male carelessness is widely shared among the campaigners. The older men in the community sometimes use the term popomama (婆婆妈妈), which can mean 'overly careful' or 'old-womanly' and carries connotations of sentimentality, to label certain low-carbon life practices as less suitable for men. Residents reuse materials in many different ways, but only some of these practices are drawn into the campaign. For example, one old man was wearing his son's cast-off clothes, which were much too big for him. He identified this reuse as a low-carbon practice, but it was not made a formal part of the campaign. A handful of female campaigners make clothes out of reused fabric and yarn which become part of the propaganda for the campaign through media reports (see, for example, Liu 2010).

\section{Low-Carbon Role Models}

Through the many campaigns they have participated in over the years and through the constant flow of party-state propaganda, people in China, especially among the older generations, have grown accustomed to the discourse of competition and the awarding of model status. To the older generations, it has become a routinized phenomenon that blends seamlessly into everyday life, leaving actually experienced and socially efficacious model status to the handful of individuals in the community who stand out by attracting media attention and by being involved in the planning and execution of most aspects of the lowcarbon life campaign. Auntie Sun, ${ }^{5}$ a retired $\mathrm{PE}$ teacher who also has experience as a community official, stands out as the main figurehead of the campaign. She is involved in most of the voluntary activities that promote the campaign, ranging from workshops teaching people how to make things like soap bars or fruit bowls out of reused materials to manning local garbage bins and explaining the principles of the garbage sorting system to people approaching them to throw things out.

The community officials in Dongping Lane work together with both the local and national media to propagate the campaign. The idea of the paramount importance of party-state propaganda permeates community governance, and just about everyone involved in the low-carbon life campaign in Dongping Lane serves as a propagandist in one way or another. Community officials sometimes cooperate very directly with reporters by co-writing articles. The role of 
the press in the campaign is not that of a simple propaganda organ working for the officials. Journalists who choose to look at the campaign are self-interested actors who may or may not see reasons to report on the various parts of the low-carbon life campaign and its key participants, and they may adopt critical stances towards parts of the campaign.

One group of retired women produce and exhibit 'low-carbon handicrafts' (低碳 手工艺品). Soap, fabric, cardboard, yarn, tea leaves and fruit peel are among the materials used in the production of these items. There is a conspicuous overlap in personnel between the most active producers of these low-carbon handicrafts and the most vocal proponents of the overall campaign who are singled out for media attention and are familiar to many people in the community. The person first and foremost associated with this project is, once again, Auntie Sun, who has given many interviews to both TV and newspapers about her low-carbon handicrafts and the staging of exhibitions. She has conducted workshops about making fragrant soap bars from leftover scraps of soap, and she has produced and exhibited bowls made out of dried pomelo peel and a pillow stuffed with dried tea leaves. Sun's rationale for making the pillow is not only that tea leaves are recycled instead of being thrown away, which saves whatever other material would have been used as stuffing, but also that the fragrance of the pillow is pleasant and can prevent insomnia. Like its producer, the tea-leaf pillow has become an icon of the campaign, embodying the connection between concerns for personal well-being and environmental concerns that characterizes local conceptions of lowcarbon life.

Among the other handicrafts producers, Auntie Rong and Auntie Wang stand out as the best known, both being vocal proponents of the campaign and objects of local media attention, as well as those other people in the community refer to on the topic of low-carbon life. Auntie Rong's best known low-carbon handicrafts include a bag made out of a pair of jeans and a medicine cupboard made from a mooncake box. 6 During interviews, Rong emphasized the pleasure of reusing things rather than throwing them away as an important motivation. Auntie Wang is known for keeping hundreds of potted plants in the stairwell of her building and for her 'green curtain', a creeping vine directed back and forth across the window over several years to provide shade, and she is also a very prolific producer of clothes made from recycled fabric and yarn. Like Rong, she derives pleasure from her lowcarbon life activities and finds that the

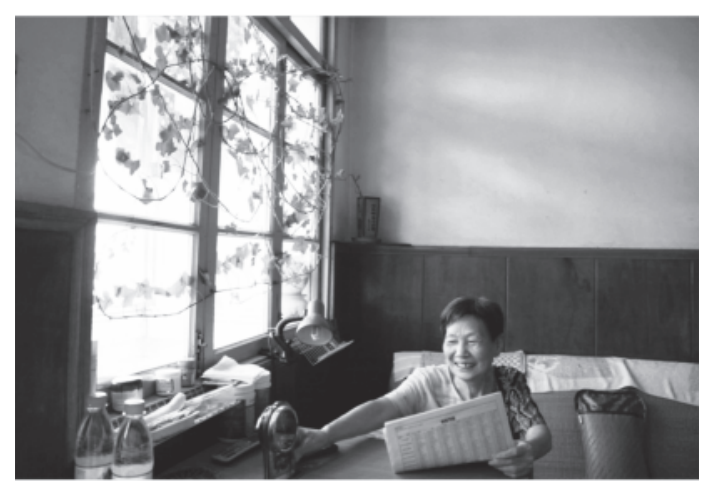

green curtain has improved the air quality in her living room.

Media reports about the campaign in Dongping Lane tend to focus on exemplary individuals, but also on physical objects such as garbage bins fitted with motion sensors and loudspeakers giving instructions in garbage sorting, composting bins for the kitchen, and the low-carbon handicrafts. This shapes the public image of the campaign, as the less conspicuous elements of the campaign, such as the use of electrical appliances in the home, or the consumption of gas, water and food, receive less attention from media than they do from campaigners. The production of handicrafts, which is limited to a handful of people, is made to stand for the campaign 
as reporters and photographers focus on Auntie Sun's tea-leaf pillow or Auntie Wang's curtain. The status of low-carbon role model becomes gendered through things because only women produce the low-carbon handicrafts. It is further gendered through the connection with officials and journalists, who highlight the lowcarbon handicrafts as markers of exemplarity.

Auntie Sun and the other core campaigners may emerge as role models for those who become involved in low-carbon life practices. However, to other residents and media consumers who have not become involved in campaigning and who may not share their ideas about the joys of reusing materials, they could be seen simply as old women who happen to spend their free time in retirement on hobby-like activities that they frame as climate change mitigation.

\section{Campaigning in a NeW Era}

A significant part of the experience that the retired residents have with voluntary work comes from the mass-mobilization campaigns of the Mao era. Local officials refer to these experiences as an important resource for the present campaign. Whereas officials, who are often too young to have experienced the poverty and political radicalism of the past, may associate the experience of the older residents with a romanticized image of a communal spirit of frugal living, the older residents situate the campaign in the present conjuncture of late reform-era consumer culture and anxiety over environmental destruction and climate change. In the words of one campaigner:

'We have money now, but that doesn't mean we can be wasteful! [...] After "reform and opening up" (改革开放) common people got more money in their pockets and began spending extravagantly. Now we have to reduce carbon. When we became aware of this, we began to economize more'.
Rather than a virtue made out of immediate material necessity, low-carbon life in Dongping Lane is a response to the recognized long-term predicament of living in an era of climate change that resonates with a distaste for waste among older people in China. ${ }^{7}$

In Dongping Lane, as in other urban communities in China, the campaign initiatives of local officials meet favorable responses primarily among the retired residents. Public discussion meetings, designated role models, monitoring and competitions are part of a repertoire of campaigning developed during the Mao era, which is familiar to the retired volunteers. Campaigning in the present involves negotiating the past to discern carefully what can usefully be recycled. Part of the repertoire begins to look outdated, especially the campaign techniques associated with Maoism such as mass mobilization and calls to emulate propaganda heroes. The exemplary individuals of the campaign in Dongping Lane come across as real people rather than idealized heroes. The values they exemplify are also different from the values of earlier models, representing a fundamental shift from heavily politicized public morality to hobby-like practical knowledge as the main focal points of exemplarity. The selfless and ascetic role models of the Mao era have been replaced with role models interested in enjoying life.

While China's consumer revolution offers people many opportunities to pursue material pleasures that were unthinkable in the Mao era, the pleasures of low-carbon life as conceived among the retired campaigners tend to be of a different kind. Distancing themselves from both the asceticism of their youth and some of the more excessive forms of consumerism taken up by some among the younger generations today, the campaigners in Dongping Lane are involved in an attempt to re-think what it means to lead good lives. Embracing the joys of nurturing plants, reusing 
materials and paying attention to the ways in which hitherto unquestioned practices can be connected with greenhouse gas emissions, the campaigners are attempting to have a good time in embedding climate change mitigation in everyday life.

Younger people who get in touch with the campaign such as journalists, scholars and visiting officials from other communities sometimes engage in discursive marginalization of the retired residents by framing their activities as a kind of 'unwitting environmentalism', implying that they do not understand climate change and are merely acting out of old habits that have nothing to do with environmental concerns. The campaigners are aware of this marginalization and resist it through explicit recasting of the preoccupations and practices of older people as climate change mitigation. Although low-carbon life is not framed as a struggle against mainstream values, the residents make ironic comments showing their awareness that some of the claims of low-carbon life can be read as implicit criticism of consumerism. An example of this use of irony was provided by Auntie Rong, who said, with a mischievous smile, that all you need in order to embrace low-carbon life is to be stingy.

Rather than unreflected habits or doctrinal allegiance to the notion of thrift, the production of low-carbon handicrafts depends on embodied skills learned in earlier times and recycled for the purpose of promoting the present campaign. Here, the older women can draw on skills that the older men either do not have or do not find it desirable to reactivate because of the associational links made between careful material practice and older women encapsulated in the expression popomama. The hobby-like activities of the older men such as calligraphy, playing mahjong and taking caged birds to the park seem to lie beyond the boundaries of what can meaningfully be categorized as low-carbon life practices according to local sensibilities. This does not prevent men from becoming involved in the campaign. A number of core campaigners are men, but their activities are less conspicuous and receive less attention than those of the producers of low-carbon handicrafts.

\section{Conclusion}

Among the campaigners in Dongping Lane, low-carbon life is understood as the idea of changing a series of everyday life consumption practices in order to reduce the emission of greenhouse gases. To begin with, the practices of low-carbon life are not explicitly coded as gendered, but in the encounter with local social categorization and conceptions of material culture aspects of campaigning become gendered nonetheless. Although both community officials and retired residents draw on experiences from the Mao era in the planning and execution of the campaign, the move away from confrontational politics focused on class struggle towards a non-confrontational approach to campaigning restricts the repertoires that can be recycled. The experiences from the Mao era that are deemed fit for recycling in the present relate to the material conditions of everyday life rather than political mobilization. The element of low-carbon life that is first and foremost associated with exemplarity is the production of handicrafts from reused materials. Standing out as an exemplary individual in the campaign requires embodied skills. Through the media's focus on a handful of older women and their lowcarbon handicrafts, the idea of exemplarity becomes gendered, as it is the women rather than the men among the core campaigners who come to stand for the campaign in media reports. The campaign is an example of what can happen when officially sanctioned requirements to reduce greenhouse gas emissions encounter a particular set of concerns and sensibilities among retired people in urban China. When low- 
carbon life becomes conceptualized not as activism but as a delicate art of slowing down material flows by employing skills acquired in earlier times, the older women come to stand out as role models. Their ideas and practices may serve as an inspiration to future generations that face the challenge of adapting the consumer lifestyles that have emerged, spread and deepened during the reform era in China to the fact that we are living in times of climate change.

\section{NoTes}

1. All these highly approximate numbers are drawn from interviews with local officials.

2. A total of 76 interviews were recorded. The typical length was around one hour and 15 minutes, but some were as short as ten minutes and some ran for well over two hours. Most of the interviews were transcribed by four different Chinese research assistants, and a few were transcribed by me. A dozen people who were the key personnel of the campaign were interviewed several times. The formal interviews were supplemented with a considerable amount of more informal interaction, and much of what I got to know about the campaign comes from these talks rather than from what ended up on 'tape'. All campaigners portrayed in photographs or referred to by their real names in this article have given their informed consent. 3 . See, for example, the introduction to the Women, Gender \& Research special issue on 'Gendering Climate Change', No. 3-4 of 2009 (Christensen, Breengaard and Oldrup 2009). 4 . The same pattern can be found among retirees in Denmark (Lausten and Sjørup 2003: 25). 5. In China, 'auntie' (阿姨) is a widely used neutral term for women of roughly the same age as the speaker's parents. Some of the oldest female campaigners were referred to as 'grandma' (奶奶). 6. Moon cakes are traditionally given as gifts at the Mid-Autumn Festival (中秋节) in China. Their packaging has become increasingly lavish in recent years.

7. For an analysis of the connections between frugality and old age in Beijing, see Anna Boermel (2006): "No Wasting" and "Empty Nesters": "Old Age" in Beijing'.

\section{LITERATURE}

- Boermel, Anna (2006): 'No Wasting' and 'Empty Nesters': 'Old Age' in Beijing, in: Oxford Development Studies 24/4/2006.

- Boland, Alana \& Zhu, Jiangang (2012): Public Participation in China's Green Communities: Mobilizing Memories and Structuring Incentives, in: Geoforum 2012/43.

- Bray, David (2006): Building 'Community': New Strategies of Governance in Urban China, in: Economy and Society, 35(4), 530-549.

- Christensen, Hilda Rømer, Breengaard, Michala Hvidt and Oldrup, Helene (eds.) (2009). Gendering Climate Change, in: Women, Gender \& Research, Vol. 3-4, 2009.

. Collier, Stephen J. and Ong, Aihwa (2005): Global Assemblages, Anthropological Problems, in: Global Assemblages: Technology, Politics, and Ethics as Anthropological Problems. Blackwell, Malden, MA.

- Dankelman, Irene (2002): Climate Change: Learning from Gender Analysis and Women's Experiences of Organising for Sustainable Development. Gender and Development, Vol. 10, No.2.

- Delman, Jørgen (2014): Climate Change Politics and Hangzhou's 'green city making', in: Berg, Per Olof and Björner, Emma (eds.) Branding Chinese Mega-Cities: Policies, Practices and Positioning. Edward Elgar, Cheltenham.

- Farquhar, Judith and Zhang, Qicheng (2012): Ten Thousand Things: Nurturing Life in Contemporary Beijing. Zone Books, New York.

- Heberer, Thomas (2009): Evolvement of Citizenship in Urban China or Authoritarian Communitarianism? Neighborhood Development, Community Participation, and Autonomy. Journal of Contemporary China, 18:61/2009.

- Kaijser, Anna and Kronsell, Annica (2013): Climate Change through the Lens of Intersectionality. Environmental Politics, 2013.

- Lausten, Mette and Sjørup, Karen (2003): Hvad Kvinder og Mand Bruger Tiden Til: om tidsmassig ligestilling $i$ danske familier. Copenhagen, Socialforskningsinstituttet.

- Liu, Dong (2010): Dongping Lane Community names 15 low-carbon model households - all have unique skills (东平巷社区评出15位低碳示范户个 个有绝活), Zhejiang Online. 2010-07-08, http://zjnews.zjol.com.cn/05zjnews/system/20 10/07/08/016745436.shtml

· Xu, Wenwen. (2010): 'Households Go Green.' Hi Center. Hangzhou English Portal. 2, 2010-0802 , http://www.hicenter.cn/columns_detail.asp?id=4 34829 